Sociohistórica, $\mathrm{n}^{\circ}$ 42, e056, 2do. Semestre de 2018. ISSN 1852-1606

Universidad Nacional de La Plata.

Facultad de Humanidades y Ciencias de la Educación.

Centro de Investigaciones Socio Históricas

\title{
El territorio como espacio de confluencias. Luchas por el hábitat urbano durante la recuperación democrática en Córdoba (1982-1987)
}

Leticia Medina

Centro de Investigaciones "María Saleme de Burnichón". Universidad Nacional de Córdoba, Argentina letmedina@ hotmail.com

Cita recomendada: Medina, L. (2018). El territorio como espacio de confluencias. Luchas por el hábitat urbano durante la recuperación democrática en Córdoba (1982-1987). Sociohistórica, 42, e056 https://doi.org/10.24215/18521606e056

Recibido: 13 Septiembre 2017 - Aceptado: 19 Abril 2018 - Publicado: 3 diciembre 2018

Esta obra está bajo licencia Creative Commons Atribución-NoComercial-CompartirIgual 4.0 Internacional

http://creativecommons.org/licenses/by-nc-sa/4.0/deed.es AR 


\title{
El territorio como espacio de confluencias. Luchas por el hábitat urbano durante la recuperación democrática en Córdoba (1982-1987)
}

\author{
The territory as a confluence place. Struggles for urban habitat during the democratic recovery in Cordoba city \\ $(1982-1987)$ \\ Leticia Medina \\ Centro de Investigaciones "María Saleme de Burnichón". \\ Universidad Nacional de Córdoba, Argentina \\ letmedina@hotmail.com
}

\section{Resumen:}

Sobre la base del análisis de archivos documentales, fuentes estatales y periodísticas y entrevistas orales, se propone una lectura histórica sobre la movilización en defensa del hábitat urbano en Córdoba durante la última recuperación democrática, atendiendo a las interacciones entre diversos actores, la articulación de demandas, los recursos movilizados, los repertorios puestos en juego y los significados otorgados por los actores -así como las justificaciones que tomaron estado público- respecto de sus propias iniciativas y de las características del contexto. Se sostiene que el hábitat configuró un campo de experiencias en el que se combinaron y coexistieron acciones disruptivas, iniciativas normalizadoras, propuestas partidarias y formas de participación desde abajo en los espacios institucionales, impulsando y ampliando los procesos de democratización en curso. La experiencia de lucha por el hábitat ofrece asimismo sugerentes pistas para avanzar en reflexiones en torno a la tensión entre lo social y lo político en la acción colectiva. Palabras clave: Hábitat, Democratización, Acción colectiva, Córdoba.

\section{Abstract:}

Based on the analysis of documentary archives, state and journalistic sources and oral interviews, it is proposed a historical reading on the mobilization in defense of the urban habitat in Cordoba during the last democratic recovery, taking into account the interactions between different actors, the articulation of demands, the resources mobilized, the repertoires put in play and the meanings granted by the actors - as well as the justifications that took public status - regarding their own initiatives and the characteristics of the context. It is argued that the habitat formed a field of experiences in which disruptive actions, normalizing initiatives, party proposals and styles of participation from below in the institutional places were combined and coexisted, impelling and expanding the ongoing processes of democratization. The experience of the struggle for habitat also offers suggestive clues to advance in reflections on the tension between social and political in collective action.

KeYwords: Habitat, Democratization, Collective action, Cordoba.

\section{INTRODUCCIÓN}

Aun antes de diciembre de 1983, la descomposición del régimen dictatorial se evidenciaba en la creciente movilización -muchas veces subterránea, pero también con episodios de visibilización pública- registrada en diferentes espacios sociales. Una vez producido el recambio de autoridades, sin embargo, la llamada "primavera democrática" -el renacimiento y la multiplicación de expresiones de libertad en el marco de la democracia recuperada- se enfrentó a diversas limitaciones. Fundamentalmente, el proceso de recomposición de la vida política y social fue tensionado por una concepción de la democracia que restringió su componente propiamente democrático: el relativo a la igualdad, la identidad entre gobernantes y gobernados y la soberanía popular (Mouffe, 2003).

El territorio de la ciudad se constituyó, en este marco, como espacio de confluencias múltiples, de configuración de actores y redes de movilización que demandaron al Estado y gestionaron recursos, y que disputaron por el sentido de la democratización. Así, en el cruce entre los problemas derivados de los procesos de urbanización en Córdoba, las disputas por las formas que debía asumir la naciente democracia 
y las trayectorias de ciertos actores políticos, es posible rastrear desde comienzos de la década de 1980 algunas acciones colectivas y expresiones organizativas que dan cuenta de las múltiples iniciativas orientadas a tensionar y construir el sentido de los procesos de democratización en relación con el espacio urbano. En efecto, aun en los meses previos a la recuperación de la democracia se registran diversas experiencias de organización, movilización y reclamo por el acceso a mejores condiciones de vida en la ciudad que, apelando a marcos de justicia e invocando los valores y principios democráticos, configuraron estructuras de movilización y ciertos sentidos públicos sobre el derecho al hábitat.

En este artículo, analizamos algunos de estos procesos de movilización alrededor de ciertos conflictos y demandas vinculados con el hábitat, con atención a las interacciones entre diversos actores, los recursos movilizados, las relaciones con el espacio en el que desarrollaron sus acciones, los repertorios utilizados y los significados otorgados por los actores -así como las justificaciones que tomaron estado público- respecto de sus propias iniciativas y de las características del contexto. Nos proponemos así dar cuenta de algunas experiencias de movilización que aportaron a la construcción de la democracia atendiendo a un aspecto fundamental en las sociedades contemporáneas: el relativo al derecho al hábitat en un espacio urbano crecientemente mercantilizado y excluyente. Experiencias que, por otra parte, permanecieron en una relativa oscuridad dentro del campo de la ciencia política, hegemonizado durante varias décadas por una perspectiva que privilegió la acción política institucionalizada por sobre otras formas del compromiso político (Rinesi y Vommaro, 2007; Solís, 2013).

El artículo propone una mirada histórica sobre las principales experiencias de movilización y acción colectiva por el hábitat entre el ocaso del gobierno dictatorial y las elecciones de 1987, momento en el que las exigencias por el acceso al hábitat lograron una significativa resonancia en la escena pública. Metodológicamente, se sostiene sobre el análisis cualitativo de dichas experiencias históricas sobre la base de fuentes documentales (revistas institucionales, folletos y otras publicaciones de las organizaciones estudiadas), orales (entrevistas a referentes de distintas organizaciones territoriales y ONG) y hemerográficas (diarios de la época) ${ }^{1}$.

La exposición se ordena en sentido cronológico, y alrededor de las principales demandas -y los actores que lograron instalarlas en el espacio público- vinculadas con el derecho al hábitat en Córdoba, desde los últimos años de la dictadura militar. En primer lugar, la lucha por la tierra emerge como un horizonte compartido por la Comisión Intervillas y la Coordinadora de Loteos Indexados, estructuras que recibieron a su vez el aporte estratégico de algunas Organizaciones No Gubernamentales (ONG) conformadas al calor de la militancia social y política. Junto con las luchas por la tierra, las demandas por el acceso a la infraestructura y los servicios urbanos, visibilizaron a nuevos y viejos actores del espacio urbano cordobés. En segundo lugar, hacia mediados de la década emerge y adquiere fuerza la exigencia por la democratización de los centros vecinales, a tono con los reclamos por la restitución de los derechos perdidos en los diferentes espacios sociales y por la normalización de las instituciones. Hacia el final del período, la contienda electoral de 1987 supuso un escenario novedoso y desafiante para las organizaciones, las cuales, en función de sus trayectorias y definiciones estratégicas, tomaron distintos caminos para garantizar el logro de sus reivindicaciones y proyectos para la ciudad.

En el cierre del artículo, proponemos algunas reflexiones en torno a las relaciones entre acción contenciosa y democracia, y problematizamos - una vez más- las tensiones entre lo social y lo político en la acción colectiva. Por otro lado, a partir de las evidencias respecto de la confluencia de una diversidad de actores y demandas en el territorio urbano, esbozamos una conceptualización acerca del hábitat como campo de experiencias que ordenó y orientó las luchas democráticas en Córdoba durante los primeros años del nuevo gobierno. 


\section{LA CIUDAD, ÁMBITO DE LA REPRODUCCIÓN Y OBJETO DE LUCHAS}

La ciudad contemporánea, ámbito privilegiado de la reproducción social, se estructura a través de una dinámica que integra -de manera diferente y desigual-a los componentes de la sociedad. La forma urbana los aspectos físicos de la ciudad-y las relaciones sociales que se despliegan en el espacio urbano constituyen una unidad que puede ser abordada distinguiendo analíticamente algunas dimensiones: la ciudad física (suelo y vivienda, infraestructuras, equipamientos y servicios), la ciudad como unidad de reproducción económica (el entramado de actividades industriales, de intercambio comercial y de servicios), las relaciones de poder (estructura de gobierno, mecanismos de toma de decisiones) y la producción simbólica de la ciudad (Pirez, 1995).

En este marco, la urbanización es a la vez un proceso y un producto que expresa y configura las relaciones de desigualdad social. Así como la estructuración de clases y grupos sociales genera un sistema de estratificación en cuyo seno se distribuyen diferencialmente los recursos (materiales, simbólicos, relacionales) y las posibilidades para el control de esa distribución, la estructura urbana es otro factor sustancial en la configuración de los sujetos y de los escenarios de disputa en las sociedades contemporáneas. Como indican Di Virgilio y Perelman (2014), el diseño urbano tiene una enorme capacidad de regular, modelar, reprimir o potenciar prácticas y cursos de acción, y lo hace a través de los rasgos que asume cada ciudad en relación con tres dimensiones:

(i) las características del segmento del mercado de tierras y el tipo [de] hábitat en el que los actores desarrollan su vida cotidiana. (ii) Las condiciones de su localización asociadas a formas diferenciales de acceso al suelo, a los servicios, a los equipamientos urbanos, a los lugares de trabajo, etc. (...) y (iii) los flujos, las circulaciones e interacciones que propone a través de las características, calidad y condiciones de acceso de los espacios públicos, del equipamiento social, de los servicios sociales básicos (salud y educación) y del sistema de transporte urbano (p. 11).

En este sentido, partimos del supuesto de que el hábitat urbano no constituye a priori un terreno fértil para la transformación de las relaciones estructurales de subordinación, así como tampoco es el escenario de la planificación como puro instrumento de la dominación a través de la regulación de las contradicciones sociales. Frente a la oscilación -presente en los estudios relevados- entre la expectativa y la resignación respecto de la potencialidad política de los movimientos sociales urbanos, proponemos entender el hábitat urbano como campo de experiencias en el cual es posible la emergencia de procesos de subjetivación política. Las conclusiones que derivan una relación inmediata entre movilización colectiva y política democrática, en el mismo sentido, deben ser contrastadas con análisis rigurosos que aborden el complejo entramado de identidades, trayectorias de los actores, políticas públicas, negociaciones y disputas de poder que indefectiblemente constituyen cualquier proceso de movilización en torno a un problema público.

Por otra parte, asumimos aquí que la unidad de conciencia y acción de un movimiento no debe tomarse como supuesto, sino como resultado de un sistema de relaciones sociales y de interacciones que deben ser analizados (Melucci, 1999), descomponiendo la unidad empírica para comprender cómo y por qué se verifican la coordinación y la acción colectiva. Desde esta perspectiva, es posible reconocer la conformación de algunas redes de movilización (Schuster, 2005) que se fueron articulando alrededor de ciertos conflictos y demandas por el hábitat durante los años 80 , algunas de las cuales confluirán posteriormente en una estructura de movilización de mayor envergadura.

Esta confluencia -que mezcló en el territorio a identidades y trayectorias militantes diversas, pobladores sin experiencias previas de acción colectiva, saberes profesionales y populares, necesidades vitales y estrategias políticas- construyó las condiciones para los procesos de organización colectiva y politización que comenzaron a registrarse en los barrios y villas de Córdoba, procesos que, según veremos, encontraron en la (re)naciente democracia un horizonte y un poderoso argumento para enmarcar las acciones. 


\section{"LA ORgANIZACIÓN SE EMPIEZA A DAR ALREDEDOR DE PROBLEMAS CONCRETOS". Estrategias PARA ACCEDER A LA CIUDAD}

En el marco de un crecimiento desordenado de la mancha urbana y del progresivo declive de las condiciones económicas de las familias, el acceso a la tierra -presente como cuestión ya desde los últimos años de la dictadura-, así como al agua, al servicio eléctrico y a las redes de gas natural, el trazado de los circuitos de transporte colectivo y la provisión de servicios de salud y educación fueron demandas que estuvieron presentes en las acciones de cada una de las organizaciones con anclaje territorial activadas durante los años 80. Una primera interpretación podría limitarse a comprender esta creciente movilización en demanda por necesidades concretas como una respuesta reactiva frente a la pérdida de ciertos bienes colectivos. Sin embargo, incorporar la mirada de los actores y la dimensión histórica de los procesos permite comprender de qué manera, tras la fuerte desarticulación de la organización política y territorial producida -represión mediante- durante la última dictadura, la lucha por necesidades materiales inmediatas, tangibles y alcanzables se constituyó en espacio de confluencia entre ciertos actores con trayectorias políticas previas -que optaron estratégicamente por la construcción de organizaciones en el espacio barrial-y comunidades afectadas por la falta de suelo, vivienda, servicios y equipamientos esenciales.

En este período, algunas organizaciones no gubernamentales (ONG) se convirtieron en actores clave en la articulación de estructuras de movilización desde los territorios, así como en la construcción de redes de solidaridad e intercambio a mayor escala. En el caso de Córdoba, durante los años 80 fueron centralmente cinco las ONG que incentivaron con distintas estrategias y acciones la organización y las luchas de los pobladores por el hábitat. El Servicio a la Acción Popular (SeAP) acompañó la conformación de la Comisión Intervillas -cuya actuación analizaremos en seguida-, mientras que el Centro de Comunicación Popular y Asesoramiento Legal (Cecopal) estimuló la organización de la Coordinadora de Loteos Indexados. Otros aportes significativos por esos años se vincularon con el trabajo del Servicio a la Promoción Humana (Serviproh), la Mutual Mugica y el Servicio Habitacional y de Acción Social (SEHAS). Una mirada hacia el interior del campo de las ONG permite identificar la diversidad de trayectorias, experiencias y contextos de surgimiento que dotaron de sus particulares identidades a cada una de estas instituciones, como veremos más adelante.

La necesidad de tierras y los conflictos por su apropiación y producción como suelo urbano se expresaron en luchas - protagonizadas por distintos actores que fueron configurando sus demandas y sus propias identidades al calor de la acción- desde los años previos a la recuperación de la democracia. Las protestas, activadas en su mayoría a partir de iniciativas estatales que afectaron a distintos grupos de ciudadanos cordobeses, se constituyeron en algunos casos en puntapié de procesos organizativos de mayor alcance en cuanto a su perduración en el tiempo y sus efectos pragmáticos en la escena pública.

Hacia el final del gobierno militar, y frente a los efectos de la Circular 1050 del Banco Central ${ }^{2}$, que establecía un nuevo sistema de indexación para los créditos hipotecarios, un equipo de abogados impulsó un espacio de consultoría técnica para los vecinos afectados, a partir del cual se incentivó la conformación de la Coordinadora de Loteos Indexados. Posteriormente, estos abogados -algunos de cuyos principales referentes provenían de la militancia política en el Partido Intransigente ${ }^{3}$-, junto a otros profesionales y militantes con trayectoria en el campo de la educación popular latinoamericana ${ }^{4}$, conformaron una asociación civil con perfil técnico-político: el Centro de Comunicación Popular y Asesoramiento Legal (Cecopal), que desarrolló su trabajo junto a la Coordinadora en los territorios en los que ésta tenía inserción a través de su intervención desde la perspectiva del derecho alternativo y la comunicación popular y comunitaria.

En mayo de 1984 el trabajo de la Coordinadora de Loteos Indexados de Córdoba -integrada por vecinos afectados por las indexaciones y con el asesoramiento del equipo de abogados-, en el marco de una fuerte movilización a nivel nacional por este tema, permitió instalar el conflicto de los deudores hipotecarios en la 
primera Asamblea Nacional Legislativa. La demanda de las organizaciones logró trascender al espacio público y se instaló como problema que debía ser atendido de manera inmediata por el nuevo gobierno.

Los reclamos de la Coordinadora se dirigieron principalmente contra las empresas privadas e inmobiliarias que lucraban con la tierra urbana -a las que denominaron "vampiros de la tierra" (Cecopal, 1990)-, mientras que el Estado fue posicionado más bien como un aliado potencial, cuyas políticas podían garantizar la protección y el acceso a los derechos de los sectores populares. En julio, el Congreso Nacional sancionó la ley $23.073^{5}$, que establecía un mecanismo para determinar el valor de los lotes, revaluar los pagos realizados y fijar nuevas escalas y modalidades de pago de los saldos adeudados. La ley nacional que protegía estos bienes de la especulación de las inmobiliarias constituyó entonces una de las primeras conquistas de los pobladores organizados en defensa del hábitat en este período.

La lucha contra la indexación de las tierras fue un proceso largo, al calor del cual se alcanzaron significativos niveles de articulación y movilización a nivel local. En 1986, la Coordinadora nucleaba ya a pobladores de sesenta y tres barrios de la capital, y se fortalecía una identidad construida firmemente alrededor de una demanda -la de protección de las pequeñas propiedades urbanas frente a la usura de un conjunto de actores privados-, pero también en torno a la propia condición social de sectores medios y medio bajos a través de la explicitación de una diferencia: entre lo que se consideraba "justo" (saldar las deudas contraídas por haber adquirido en el mercado un lote o una casa) y otras prácticas de asistencia estatal hacia sectores de pobreza estructural, sin capacidad de acceder a créditos para tierra y vivienda.

Paralelamente, desde comienzos del período democrático, pobladores de distintas villas de la ciudad, organizados -en algunos casos- bajo la forma de cooperativas y mutuales, iniciaron procesos de articulación sectorial en distintos agrupamientos con el asesoramiento de otras organizaciones no gubernamentales dedicadas a la promoción social y el hábitat popular. Un hito fundante de una de estas redes -la Comisión Intervillas (CI) - fue la Marcha Villera realizada el 25 de octubre de 1983, pocos días antes de las elecciones convocadas por la Junta Militar aún gobernante. Tras las consigna “ ¡No nos moverán. Tendremos la tierra!” ${ }^{6}$, cientos de personas de distintas villas de Córdoba se movilizaron por el centro de la ciudad, trazando un recorrido que evidenciaba la intención de instalar la protesta en el espacio público. En efecto, la marcha se desplazó por dos plazas céntricas, se detuvo frente a la sede del diario La Voz del Interior, y culminó en la Casa de Gobierno de la provincia exigiendo a las autoridades la suspensión de todos los desalojos en marcha, y "una solución definitiva a través de la expropiación y cesión de la tierra en condiciones adecuadas" 7 .

La Marcha Villera fue una novedosa y contundente respuesta de las organizaciones nucleadas a partir del conflicto por el intento de desalojo del Establecimiento San Jerónimo, un asentamiento precario con más de 30 años de historia en la zona norte de la ciudad. A partir de la orden judicial, emitida tras la demanda de una fundación privada ${ }^{8}$ que reclamaba la propiedad de los terrenos, algunos vecinos de San Jerónimo comenzaron a buscar apoyo para enfrentar un desalojo que parecía inevitable. En pocos meses, un conjunto de villas urbanas que atravesaba conflictos legales en relación con las tierras sobre las que se asentaban comenzaron a movilizarse en reclamo de soluciones, afirmados sobre formas incipientes de articulación. En julio del año siguiente, nuevos conflictos por intentos de desalojo adquirieron visibilidad pública, y comenzó a instalarse el nombre de la Comisión Intervillas a partir de la diversificación de las acciones emprendidas: además de marchas por el centro de la ciudad y concentraciones frente la Legislatura provincial ${ }^{9}$, la CI presentó a la Cámara de Diputados un proyecto de ley de expropiación de tierras para la construcción de viviendas populares en 1984, y en 1985 envió nuevamente una nota al bloque de la UCR exigiendo la urgente resolución de las amenazas de desalojo que pesaban sobre distintas villas de Córdoba. Al mismo tiempo, desarrolló una estrategia de difusión de sus acciones a través de los medios de comunicación ${ }^{10}$, por la que recibió la solidaridad de algunos actores significativos de la escena política local. ${ }^{11}$

Dos elementos resultan clave para comprender la magnitud de la respuesta a esta nueva maniobra de ciertos actores económicos que, amparados por el poder dictatorial, habían logrado apropiarse de numerosos 
terrenos en zonas estratégicas de la ciudad. Por un lado, el contacto de algunos referentes de las villas de Córdoba con las experiencias de ocupación de tierras que, en los primeros años de la década, venían desarrollándose en otras localidades. En efecto, las primeras reuniones de lo que poco después sería la Comisión Intervillas contó con la presencia de una delegada del asentamiento de Quilmes, proceso de ocupación registrado hacia fines de 1981 en el partido del mismo nombre y que garantizó el acceso a la tierra y la vivienda a unas 4.600 familias. A su vez, la experiencia organizativa desarrollada alrededor de estas tomas en el Gran Buenos Aires había contado con el apoyo de religiosos católicos vinculados a la llamada "Iglesia de los pobres" ${ }^{12}$, algunos de los cuales venían de protagonizar experiencias similares en Brasil (Izaguirre y Aristizabal, 1988).

En segundo lugar, la organización de tales reuniones y la acción legal de los villeros frente a los desalojos recibieron el apoyo del Servicio a la Acción Popular (SeAP), una asociación civil integrada por militantes y profesionales dedicada al trabajo de promoción social. En estas redes conformadas aun en contextos de represión y dictadura fue significativo el apoyo de organizaciones con distintas identidades; principalmente, ONG de tipo profesional y perfil técnico y entidades vinculadas a la Iglesia que brindaron cierta protección y contención a los pobladores movilizados. En el caso de la Marcha Villera, el Servicio de Paz y Justicia (SERPAJ) y el Centro Ecuménico Cristiano de Córdoba (CEXC) ${ }^{13}$ participaron junto con el SeAP en las convocatorias previas a la Marcha y adhirieron públicamente a los reclamos expresados por los villeros. En el mismo sentido, otras organizaciones no gubernamentales con distintas trayectorias e intervenciones en el territorio urbano cordobés se constituyeron en promotoras de la acción colectiva alrededor de la cuestión del hábitat, como se verá también en los años posteriores.

La CI continuó desarrollando acciones públicas al tiempo que ampliaba y consolidaba sus redes a nivel local. En junio de 1985 se realizó el Primer Encuentro Intervillero de la ciudad de Córdoba, en el que participaron referentes de ocho villas urbanas. Las conclusiones del Encuentro se enunciaron en la forma de tareas para la conducción de la CI: promover la organización y la comunicación entre las villas, brindar educación popular y garantizar la formación de los dirigentes villeros ${ }^{14}$. Pocos meses después, el SeAP respondió con un ciclo de formación de dirigentes y con un taller de periodismo popular, que dio como resultado el lanzamiento del periódico Aqui estamos los villeros, editado entre octubre de 1985 y finales de 1990.

A través de las páginas de esta publicación pueden identificarse dos elementos centrales que dan cuenta de los procesos de politización que se gestaban por esos años en los barrios de Córdoba. Por un lado, la invocación a la participación, la organización y la unidad de los villeros en el marco del nuevo contexto democrático, que apelaba a un lenguaje de derechos que ya se encontraba disponible en la sociedad en general y en la historia de las luchas por la tierra y la vivienda en particular. La conexión entre ambos tópicos -la democracia y los derechos- encuentra un matiz particular: el sistema democrático aparece como "escenario" que garantiza mejores condiciones para la participación y la lucha, al tiempo que la democracia realmente existente se cuestiona en relación al funcionamiento de los partidos y la manipulación con fines electorales:

El clima de democracia debe servirnos cada vez más para afianzar nuestras organizaciones villeras. Para eso tenemos que aumentar la participación de todos los compañeros y compañeras. Por eso, esperamos el próximo año seguir luchando por nuestras reivindicaciones 15

"La CI no tendría que ser apolítica, pero sí apartidaria. (...) Los partidos políticos al servicio de la CI, y no la CI al servicio de estos" 16 .

La diferencia con el sistema de partidos políticos se convirtió en marca de identidad del movimiento villero, que eligió como slogan de su publicación la frase "Periódico popular sin orientación partidaria". Esta perspectiva era compartida por el propio SeAP, cuyo trabajo en las villas de Córdoba se sostenía sobre la base de una fuerte crítica a los partidos tradicionales, y en la defensa de mecanismos de participación y discusión permanente en las bases de las organizaciones. 
El otro elemento que evidencia la revista es el trabajo de construcción de redes y articulación de una estructura de movilización cada vez más amplia y apoyada en la solidaridad de otros actores locales y nacionales. En la columna "Andando por los gremios" del periódico villero, la CI comenzó a entablar diálogos con algunos sindicatos locales ${ }^{17}$, mientras que en la sección "Andando por las villas" se relataban los procesos organizativos y las problemáticas de distintos asentamientos de la ciudad, con el objeto de evidenciar las similitudes y socializar experiencias de acción colectiva. En el mismo sentido, referentes de la Coordinadora participaron en distintos eventos para el intercambio y la articulación sectorial convocados por ONG y otras entidades: el Congreso Nacional de Estudiantes de Servicio Social realizado en la Universidad Nacional de Córdoba (UNC) en abril de 1985; el Encuentro de Cooperativas en Carlos Paz, organizado por la Cooperativa 25 de mayo, la ONG Serviproh y el Centro de Investigación y Perfeccionamiento en Administración Cooperativa (CIPAC) en noviembre de 1985; el II y III Encuentro Intervillero realizados en diciembre de 1985 y noviembre de 1986 respectivamente, y el Encuentro de Dirigentes de Comisiones y Cooperativas Villeras en junio de $1987^{18}$, entre otras actividades. La participación de la CI en el Congreso de estudiantes de Servicio Social revela en particular la vinculación entre esta organización y las instituciones universitarias - principalmente la UNC-, cuestión que se reitera en las diferentes experiencias de movilización en torno al hábitat. En este caso, una buena cantidad de militantes que transitaban por los barrios y villas de la ciudad tenían en común la pertenencia a la entonces Escuela de Servicio Social de la UNC, un espacio que era a la vez territorio de disputas contra otros modos de entender la profesión, y espacio de articulación de las diferentes apuestas y experiencias en el territorio.

En el conjunto de acciones y redes protagonizadas por la CI, el acceso a la tierra se revela como una demanda articuladora de la organización y la movilización desde las villas. En el documento de Propuesta a lospartidos políticos elaborado por la CI en vísperas de las elecciones de 1987, que analizamos más adelante, se retoma como principal demanda la cuestión de la tenencia de la tierra, y se denuncia un "estado de injusticia social", resultado de la combinación de tres procesos concurrentes: la falta de recursos económicos de los pobladores de las villas (desocupación, bajos salarios), la especulación por parte de los dueños de la tierra y la falta de regulación estatal sobre el mercado del suelo. Frente a esta situación, las organizaciones apelaron a un marco de justicia que invocaba como principio superior compartido el respeto por la legalidad y las normas constitucionales, recientemente restituidas:

\section{Ante esta situación contradictoria, donde por un lado el Estado dispone del derecho de todo ciudadano a la tierra, y por el otro la realidad nos muestra que un gran número de ciudadanos no la puede adquirir, QUE EL ESTADO CUMPLA CON LO ESTABLECIDO EN LA CONSTITUCIÓN NACIONAL Y PROVINCIAL, INTERVINIENDO A FAVOR DEL QUE NO TIENE TIERRA ${ }^{19}$.}

De este modo, el contraste entre la vida ofrecida a los pobladores de la periferia y los postulados establecidos en las normas constitucionales se utilizó para poner la cuestión del espacio en tela de juicio (Lefebvre, 1974) en la arena pública, en la medida en que se dejó planteado el incumplimiento de ciertos derechos y la desigualdad en la distribución de los recursos básicos que garantizaban la inclusión en la vida urbana. Más allá de los partidos, las demandas por la tierra se articularon tempranamente en el centro de los procesos de organización y movilización desde las villas de Córdoba, a partir de experiencias políticas ancladas en los territorios, y en lucha por el espacio urbano en el tránsito entre la dictadura y la democracia. Como queda claro en las expresiones de un dirigente villero en el marco de un evento público, este proceso de politización tuvo importantes consecuencias en las propias subjetividades, así como en la conformación de redes de solidaridad para la acción colectiva:

Para nosotros es importante estar acá porque nos sirve como aprendizaje para ir perdiendo el miedo a hablar y decir lo que creemos y pensamos. Para que se sepa quién es y cómo vive un villero y también por qué hay villeros. Para que sepan, entiendan y apoyen nuestra lucha ${ }^{20}$. 
En efecto, por estos años buena parte del esfuerzo de los actores movilizados se concentró en la construcción de formas de articulación y solidaridad horizontal que permitieran dar sustento a organizaciones que disponían de escasos recursos materiales y simbólicos para afrontar los desafíos políticos planteados. Activistas formados en distintas experiencias y con variadas trayectorias previas se reencontraron en la promesa de una democracia por hacer, y se involucraron en las instituciones y en los distintos espacios sociales con la mirada puesta en la reconstrucción de los lazos sociales para la dinamización de la acción colectiva.

En la misma clave pueden leerse algunas otras experiencias organizativas desarrolladas en los primeros años de la democracia, momento en el cual -en palabras de un dirigente barrial- "la lucha comienza a darse alrededor de problemas concretos". Es así como la revista Barrial -una herramienta de elaboración y difusión de la agenda vecinalista, impulsada por actores con experiencia de militancia en la dictadura ${ }^{21}$ - dedica las tapas de su segundo y tercer número a difundir informes sobre el gas y sobre el agua en Córdoba, mientras que la quinta edición ${ }^{22}$ analiza el sistema de transporte urbano. En todos los casos, la Barrial registra y expone públicamente el descontento de los vecinos en relación con las carencias de los servicios en los barrios populares y de clase media-baja, a la vez que expresa demandas al Estado en torno a una mejor provisión de los mismos apelando a un marco de derechos y de igualdad en el contexto de la naciente democracia.

En el marco de las deficiencias de su cobertura, los costos y las modalidades de prestación de los servicios y la obra pública fueron objeto de controversias durante la reconstrucción de la democracia. Hacia fines de 1985, a raíz de un conflicto con los trabajadores nucleados en el sindicato, el municipio dispuso una reestructuración del servicio de transporte urbano que implicó la cancelación de ciertos recorridos que unían a los barrios periféricos entre sí y con el centro de la ciudad ${ }^{23}$. A partir de esta modificación en los recorridos, agravada por el incremento del $30 \%$ en el costo del boleto unos meses después, a comienzos de 1986 se formó la Coordinadora de barrios de la zona sur, que desarrolló acciones de protesta exigiendo la restitución de las líneas de transporte ${ }^{24}$. La visibilidad pública de la Coordinadora incentivó a otras comunidades -algunos de cuyos referentes participaron en reuniones de este espacio y replicaron la experiencia en sus propios barriosy se afianzaron de este modo algunas redes incipientes construidas previamente.

Los casos analizados evidencian la coexistencia de diversas expresiones organizativas en los territorios durante la reconstrucción de la democracia. Por un lado coexistían las comisiones y centros vecinales formalizados en las ordenanzas municipales, cuya normalización institucional implicó un proceso conflictivo en torno a los alcances y sentidos de la democracia, como veremos en seguida. Por otro lado, junto con estos espacios institucionalizados las comunidades desarrollaron distintas formas de organización orientadas a la solución de necesidades y problemas concretos de manera colectiva: las coordinadoras, comisiones de vecinos y mesas de trabajo con temas específicos se multiplicaron en los barrios de Córdoba como alternativa de abordaje colectivo a los problemas comunes, lo que evidenciaba ya un cierto distanciamiento de los vecinos respecto de los canales políticos institucionalizados.

En este sentido, y en paralelo al trabajo de los partidos políticos -cuya acción durante la década del ochenta estuvo centralmente orientada a los procesos de democratización institucional-, en los territorios de la ciudad comenzaban a florecer organizaciones barriales cuyo desarrollo permaneció desatendido por buena parte de la ciencia política. Como sostiene Solís (2013), durante la recuperación de la democracia los partidos políticos recibieron una atención privilegiada por parte de los analistas, mientras que permanecieron en las sombras ciertas formas organizativas y alternativas de acción que dinamizaron los modos del compromiso político en la posdictadura.

De esta manera, la demanda por el acceso a la tierra y a los servicios vitales en los barrios y villas de Córdoba constituyó un eje ordenador de las luchas a lo largo de todo el período. En algunos casos, los conflictos derivados de las desigualdades en la distribución y acceso a los bienes urbanos fueron construidos por los activistas como oportunidades para la acción, y generaron condiciones para la movilización de poblaciones sin trayectorias previas en ese sentido. Estas experiencias contenciosas estuvieron en la base de la conformación 
de un amplio conglomerado de organizaciones que, a mediados de los años 80 , comenzaron a transitar algunas experiencias de (re)articulación sectorial.

\section{VECINALISMO Y DEMOCRACIA: LA LUCHA POR LA NORMALIZACIÓN DE LOS CENTROS VECINALES}

En el marco de la recuperación de la democracia, luego de siete años de gobierno autoritario -con un saldo de miles de muertos, desaparecidos y exiliados, junto con un fuerte disciplinamiento de la sociedad civil en base al terror y la desarticulación de las organizaciones-, las demandas de normalización de las instituciones ancladas en los territorios y de participación en las políticas públicas tuvieron una significativa presencia en el discurso de los actores movilizados en los territorios de la ciudad.

En ese contexto, a comienzos de 1985, el Ejecutivo de la Municipalidad de Córdoba impulsó un proceso de normalización de los centros vecinales, muchos de los cuales habían sido intervenidos o cerrados durante la dictadura militar. La iniciativa recibió fuertes críticas de algunas agrupaciones organizadas en barrios y villas, que respondieron con una convocatoria propia lanzada desde la revista Barrial. El Encuentro Vecinalista, organizado por la Barrial, se desarrolló el 18 de mayo de 1985 en la Facultad de Arquitectura de la Universidad Nacional de Córdoba, y contó con la participación de distintos actores comunitarios y organizaciones técnicas vinculadas con estas experiencias. En este encuentro se produjeron las primeras articulaciones entre el grupo de Barrial, algunas ONG que trabajaban en los territorios y la Comisión Intervillas, uno de cuyos referentes fue orador en el evento:

Estamos abocados a reunir a todos los villeros de Córdoba, para que nuestra voz sea escuchada. Si somos villeros no es porque nos guste, sino porque no podemos adquirir terrenos donde construir la vivienda. Otro de nuestros objetivos es fortalecer la democracia a través de la verdadera participación popular, logrando lo que tanto se proclama: integración y dejar de ser ciudadano únicamente en época de elecciones 25 .

De esta manera, se evidencia en la construcción de estas organizaciones una incipiente articulación entre un horizonte político democrático, vinculado a la recuperación de la participación y el protagonismo popular en la definición del tipo de sociedad que se estaba configurando, y la reconstitución de los lazos sociales y las formas más elementales de acción colectiva alrededor de la resolución de problemas y necesidades inmediatas vinculadas con el espacio urbano. Al mismo tiempo, el Encuentro configura y expresa una confluencia de trayectorias sumamente diversas alrededor del horizonte de recuperar al vecinalismo como una herramienta fundamental en el proceso de reconstrucción de la democracia. En torno a esta apuesta -bajo el lema "El Vecinalismo se pone de pie" ${ }^{26}$ - se va conformando una red en la que participan la Universidad Nacional de Córdoba y la Facultad de Arquitectura - muchos de cuyos docentes están vinculados a las agencias estatales encargadas de la cuestión urbana-, algunas ONG dedicadas al hábitat, más de 90 organizaciones vecinales, el grupo de la revista Barrial, y un centenar de organizaciones sociales y políticas que manifestaron su adhesión al evento, entre las cuales se cuentan los primeros organismos de derechos humanos de Córdoba, sindicatos, federaciones estudiantiles y centros de estudiantes, entre otras.

Como resultado del encuentro se elaboró el Manifiesto de los Barrios, que fue difundido por distintos medios de comunicación comunitarios e institucionales. Además de la recuperación de la historia del vecinalismo cordobés ${ }^{27}$ y de la descripción de las carencias y dificultades materiales que aquejaban a las comunidades, el Manifiesto expresaba una fuerte crítica al proceso de institucionalización de los centros vecinales impulsado por el Ejecutivo municipal. Según las denuncias de las organizaciones, la iniciativa oficial limitaba la autonomía política de los centros vecinales y reordenaba las jurisdicciones, lo cual forzaba a unos 150 centros a desaparecer. Frente a esta propuesta de normalización, estructurada sobre un conjunto de principios democráticos formales y conducida por el Estado, el encuentro vecinalista proponía impulsar un proceso de democratización basado en la participación popular y en la articulación entre los diferentes actores 
barriales, con la conformación de la Coordinadora Vecinalista de Córdoba, un actor político independiente del Estado.

La Coordinadora se integró inicialmente con los centros y comisiones vecinales y organizaciones barriales que habían participado en el $1^{\circ}$ Encuentro Vecinalista. Se trataba de unas 90 organizaciones, que dieron continuidad a aquel encuentro con la organización de eventos para la juventud vecinalista y las mujeres vecinalistas, así como algunas actividades en los barrios. Durante el proceso de elaboración y discusión institucional de la nueva ordenanza de Centros Vecinales, la Coordinadora realizó diversas actividades de difusión y presión hacia los partidos políticos, el Concejo Deliberante y los medios de comunicación ${ }^{28}$ - La revista Barrial continuó siendo el principal medio para expresar públicamente el rechazo no sólo a la Ordenanza de normalización de los centros vecinales -cuya aprobación formal se produjo varios meses después, en octubre de $1985^{29}$-, sino también frente a la continuidad de ciertos mecanismos propios del gobierno autoritario, como la designación desde el Municipio de interventores al frente de los centros vecinales.

Si bien la experiencia de esta Coordinadora fue acotada en el tiempo, logró elaborar una serie de puntos programáticos que articulaban diversas dimensiones de la vida urbana expresando su concepción acerca de la vinculación intrínseca entre lo social y lo político. Los cuatro puntos reclamados eran: la realización de elecciones libres en todos los centros vecinales existentes; la sanción de una ordenanza de centros vecinales acorde a la realidad de los barrios y de sus estrategias de organización; la regulación estatal sobre las tarifas del transporte urbano, y el cumplimiento de las disposiciones económicas nacionales vinculadas al control de precios y el abastecimiento ${ }^{30}$, en un contexto de alza generalizada de precios que se agravaba desde mediados de la década. El marco movilizador desde el que se impulsaron estas demandas -siempre en tensión con las concepciones formales y nunca en relación de antagonismo con el Estado- puede resumirse en el slogan de tapa de la revista Barrial: "Participando en defensa de la democracia".

Con posterioridad a la efectiva sanción de la ordenanza de centros vecinales -que prácticamente no incorporó modificaciones al proyecto original-, las organizaciones que se habían movilizado previamente iniciaron una nueva etapa de la lucha, orientada a exigir el cumplimiento de los procesos de normalización según las disposiciones de la nueva normativa. En ese marco, Barrial y la Coordinadora demandaron la constitución de comisiones normalizadoras en todos los centros vecinales, y acompañaron la conformación de listas amplias y plurales en los barrios para garantizar la participación de los vecinos en las elecciones correspondientes. En agosto de 1986, con el proceso de normalización ya en marcha, la Coordinadora Intervillas y el grupo de Barrial acordaron avanzar por el camino de la democratización de los centros vecinales, y alentaron a las comunidades de las villas a incorporarse a este proceso formando sus respectivas comisiones normalizadoras y listas para las elecciones.

Los movimientos y conflictos en torno a la normalización de los centros vecinales permiten dar cuenta, por un lado, de la productividad de las coyunturas en las que se dirimen procedimientos e instrumentos formales de la vida en democracia como momentos que facilitan la inscripción pública de demandas y la acción contenciosa en torno al sentido de tales cambios. Pero, a la vez, muestran el papel protagónico de un conjunto de actores que identificaron allí una oportunidad para intervenir en el proceso de recomposición de la vida asociativa en los barrios, activando redes previas y construyendo nuevas alianzas, no sólo para la formulación de un proyecto alternativo de ordenanza, sino posteriormente en la disputa por la efectiva democratización de los centros vecinales. La lucha por la institucionalización de la democracia en los barrios supuso, asimismo, un ensanchamiento de la cuestión del hábitat urbano, al incorporar las demandas de participación política de los vecinos en los ámbitos donde se abordaban asuntos vinculados con la vida cotidiana en la ciudad. 


\section{CONSTRUCCIÓN BARRIAL Y POLÍTICA PARTIDARIA: DILEMAS Y ALTERNATIVAS EN EL ESCENARIO ELECTORAL}

El año 1987 estuvo marcado por la agenda internacional y los usos que algunas instituciones hicieron de la declaración del Año de los Sin Techo ${ }^{31}$, pero también por la agenda local puesto que en octubre de ese año se realizaron las elecciones legislativas y ejecutivas de cargos municipales y provinciales. En ese marco, distintos actores movilizados alrededor de demandas por el hábitat desarrollaron acciones en función de estrategias diversas, que en algunos casos implicaron fuertes debates. En la disyunción de los caminos recorridos por dos de los actores que venimos siguiendo -y cuyo trazado irá produciendo posteriormente nuevos encuentros y desencuentros- se vuelve evidente la importancia de analizar los procesos de política contenciosa atendiendo a la imbricación entre los episodios de acción no convencional y la política institucionalizada (Mac Adam, Tarrow y Tilly, 2005), como modo de comprender las características históricamente específicas de las dinámicas de movilización social. Desde esta perspectiva es posible atender a las maneras en que los conflictos y demandas por el hábitat fueron conformando un campo de experiencias en el que se combinaron y coexistieron acciones disruptivas, iniciativas "normalizadoras", propuestas partidarias y formas de participación "desde abajo" en los espacios institucionales, que impulsaron y tensionaron de diversos modos los procesos de democratización en curso.

Por un lado, desde el SeAP y la Comisión Intervillas se impulsó un ciclo de actividades orientadas a articular una voz capaz de incidir en el escenario electoral local: en una serie de encuentros y talleres de discusión y producción se elaboró, por un lado, un documento público con las reivindicaciones de las organizaciones villeras; además, se planificó una actividad pública de presentación de las demandas a todos los candidatos. En junio de 1987 se realizó el Encuentro de Dirigentes de Comisiones y Cooperativas Villeras, en el cual se analizaron las problemáticas del sector y se delinearon posibles soluciones. Pocos días después se organizó el Taller de Mujeres Dirigentes del Sector Villero, en el que se articularon propuestas para el abordaje de las problemáticas que venían analizándose en espacios de reunión previos. En forma paralela, los grupos de jóvenes de las distintas villas acordaron los principales problemas específicos de la juventud y algunas soluciones posibles. Esta alternativa de acción frente a la coyuntura electoral se asentaba en una lectura particular acerca del sistema de partidos políticos, así como del rol de la militancia partidaria durante los años previos, y recurría a otras tradiciones y aprendizajes para apostar a una politización del trabajo social en las villas por fuera de las estructuras partidarias clásicas.

Finalmente, entre el 24 y el 26 de julio se desarrolló el Encuentro de Organizaciones Villeras en la localidad de Alta Gracia, distante a unos $35 \mathrm{~km}$ de la capital cordobesa, en el que confluyeron los debates y propuestas elaborados previamente. El intenso intercambio de experiencias y articulación sectorial permitió, entre otros resultados, la elaboración de un documento de "Propuestas del sector villero", en el que se recogieron las conclusiones de las comisiones de trabajo en torno a los temas planteados: tierra y vivienda, salud y alimentación, infraestructura y servicios, educación y guarderías, trabajo, recreación, y deporte y cultura.

El 20 de agosto, la CI convocó a los candidatos de los diferentes partidos a una actividad pública con el objetivo de instalar las demandas del sector villero en la agenda electoral de todas las fuerzas. El acto se realizó en el céntrico Teatro Maipú, y asistieron la mayoría de los referentes de los partidos, excepto la UCR. La CI escuchó a los candidatos y presentó su "Documento de propuesta a los partidos políticos", que también había sido difundido a los medios de comunicación a través de gacetillas y de una conferencia de prensa realizada previamente.

En estas acciones queda de manifiesto la voluntad y decisión de la organización de articular las acciones orientadas a abordar las problemáticas concretas del sector con la dinámica política más general, en función de un tipo de democracia que debía garantizar las respuestas a las necesidades sociales, pero en el que los límites entre lo social y lo político -y por consiguiente, las tareas y responsabilidades de unos y otros actoresquedan claramente demarcados: 
...la DEMOCRACIA garantiza nuestros DERECHOS, por esta razón y en ejercicio de los mismos, elaboramos PROPUESTAS que queremos presentar a TODOS LOS PARTIDOS POLÍTICOS para que incluyan en sus planes de gobierno ${ }^{32}$.

De esta manera, se evidencia ya tempranamente la capacidad e iniciativa de los dirigentes villeros en relación con la visibilización de las demandas y propuestas a partir de la interpretación y construcción de oportunidades políticas, la planificación de acciones públicas y la articulación de un discurso sobre la ciudadanía que cuestionaba los límites de la democracia formal. Al mismo tiempo, quedaba expuesta también la fractura -cuyo origen e historia resulta imposible de rastrear en el marco de este trabajo, pero que seguramente se profundizó durante los años de la dictadura- entre las militancias populares y el sistema de partidos políticos, al menos en una parte de las experiencias de movilización postdictadura.

Pero, por otra parte, el escenario electoral es el contexto de gestación del Movimiento Cordobés (MC), un partido político construido sobre las redes y experiencias territoriales desarrolladas en torno a la revista Barrial en los años previos. Sobre la base de esa construcción territorial, y con la Barrial como órgano de prensa ya consolidado, el grupo constituyó el Movimiento Cordobés ${ }^{33}$, que contó entre sus filas con referentes de la lucha contra la dictadura en los años 70. Desde las páginas de la revista se estableció una contraposición entre la concepción de la democracia que sustentaba el Estado municipal, que despreciaba la participación popular en los procesos de normalización institucional, y otra que revalorizaba el papel de las organizaciones intermedias

...como instancia donde los vecinos ejercen la democracia de manera directa y por lo tanto definen sus necesidades y (...) sus intereses así como desarrollan la crítica y el control constructivo del estado ${ }^{34}$.

De esta manera, Barrial proponía un proyecto vecinalista basado en la democracia participativa, en oposición a las políticas municipales del gobierno -consideradas autoritarias-, pero también a los límites de la democracia "formal" practicada por el gobierno radical. Desde esta posición, el grupo cuestionaba las propuestas oficiales vinculadas con los procesos de normalización y proponía alternativas basadas en la participación directa de los vecinos organizados. En 1985, como vimos más arriba, Barrial trabajó intensamente alrededor de la iniciativa para democratizar los centros vecinales. En 1987, hizo lo propio en relación con la reforma de la Constitución Provincial, denunciando que

...lo que debería ser un gran debate democrático y participativo acerca del país que queremos, de la provincia que necesitamos, de lo que aspira el pueblo de Córdoba en derechos sociales, en derechos laborales, en educación, en salud, en vivienda, en derechos humanos, etc. queda relegado frente a un desvergonzado acuerdo para conseguir la reelección del gobernador ${ }^{35}$.

En ese marco, en 1986 el grupo de militantes de la Revista Barrial explicitaba en las páginas de la publicación su decisión de conformar una opción política capaz de intervenir en las elecciones municipales del año siguiente. La decisión se fundamentó públicamente en el reconocimiento acerca de los límites alcanzados por el movimiento vecinalista, cuyo papel había sido fundamental en la recomposición de los lazos y en la reconstrucción de formas de democracia directa y participativa. Sin embargo, se evaluaba también que las políticas autoritarias, intervencionistas y no participativas impulsadas por los funcionarios de los partidos históricos conspiraban contra los esfuerzos realizados por los vecinos. Por eso, resultaba "imprescindible" construir

...NUEVAS FORMAS DE REPRESENTACIÓN para participar en las elecciones municipales, para que aquellos que nos representan en el Concejo Deliberante sean hombres y mujeres salidos de los propios barrios ${ }^{36}$.

De esta manera, el Movimiento Cordobés se presentó como una alternativa partidaria basada, según indica Solís (2013), en el reconocimiento de "la necesidad de articular nuevas formas de representación que, sin desdeñar lo electoral, se orienten a profundizar el proceso organizativo y de articulación barrial” (p.16). Más allá del derrotero político del MC, la recuperación de esta experiencia de articulación barrial devenida 
en alternativa político-partidaria nos permite evidenciar otros modos de resolver las tensiones entre la construcción barrial "desde abajo" y la institucionalidad política. Si para el movimiento villero el desafío fue visibilizar los problemas y demandas del sector, y lograr su incorporación en la agenda político-electoral de los partidos, preservando su identidad como actor autónomo respecto de los mismos, el grupo de Barrial apostó a tensionar el modelo de democracia que se consolidaba a nivel municipal y provincial a través de la conformación de una estructura partidaria basada en mecanismos de democracia participativa, antivanguardista y asentada en el crecimiento de las tramas organizativas de los barrios. En síntesis, se trató de un proyecto vecinalista "democrático y participativo", que planteaba una confrontación abierta con el modelo de democracia representativa con resabios autoritarios hegemónico en el período.

Las estrategias desplegadas por estos colectivos frente a la coyuntura electoral ofrecen una clave para dar cuenta de la construcción de otros sentidos sobre la democracia, con anclaje en las experiencias de organización villera y barrial. Estas alternativas de acción se desarrollaron durante toda la década del ochenta y, más allá de los resultados obtenidos en términos prácticos (la cantidad de votos logrados por el Movimiento Cordobés y la efectiva incorporación de las demandas en las agendas de los partidos políticos, entre otros indicadores), plantean una pista sugerente en relación con la cuestión de la politicidad de la acción colectiva en los territorios. En efecto, como hemos visto, el espacio urbano resultó atravesado por una diversidad de iniciativas, conflictos, demandas y actores que en determinadas coyunturas -y merced al trabajo de activistas con distintas trayectorias políticas- hicieron del territorio un lugar de confluencias para la acción colectiva. En las experiencias destacadas aquí, además, el territorio no fue un mero escenario sino que se constituyó siempre como objeto de conflictos, a partir de las tensiones generadas por la falta de acceso a determinados bienes y servicios urbanos, la propiedad de la tierra y las formas instituidas de participación, entre otros asuntos.

En términos históricos, estas actuaciones expresan una cierta distancia respecto de la experiencia de vinculación entre lo social y lo políticoanalizada por Merklen en el caso de los asentamientos del Gran Buenos Aires, en donde el vínculo con el sistema de partidos políticos supuso la integración de las organizaciones barriales al juego de la competencia política, con lo cual "la autonomía de las organizaciones se pierde definitivamente y en los asentamientos desaparece la unidad" (Merklen, 1997, p. 9). Por el contrario, la experiencia de Intervillas en la coyuntura electoral de 1987 permitió dinamizar los debates internos entre las comunidades villeras y la elaboración de un pliego de demandas que ordenó la acción en función de objetivos comunes, mientras que la interpelación a los candidatos instaló en la escena pública la voz de la Comisión Intervillas como sujeto capaz de convocar a los partidos políticos y de formular demandas en nombre del conjunto de los excluidos de la ciudad. Por su parte, como afirma Solís (2013), la experiencia que se extendió desde la revista Barrial al Movimiento Cordobés supuso un proceso de politización del territorio de la ciudad, a partir de la promoción de la acción colectiva y la recomposición del tejido social desmantelado durante la dictadura. Este proyecto político, construido desde las necesidades y demandas sentidas en los barrios populares de una ciudad que se volvía cada vez más ajena, permitió además el encuentro de activistas de distintas generaciones y con diversas trayectorias, que en los años de la recuperación de la democracia propusieron un modo de entenderla -y de prac

\section{A MOdo DE SÍNTESIS: DEMOCRACIA, UN HORIZONTE COMÚN EN LA LUCHA POR EL HÁBITAT}

Las intensas transformaciones en la estructura urbana de Córdoba desde mediados del siglo pasado -y su impacto en la desigual distribución y accesibilidad a los bienes y servicios urbanos-configuraron una serie de conflictos públicos de diversa envergadura y con diversos resultados en la década de los ochenta. Al mismo tiempo, el escenario de recuperación de la democracia -luego de un período de represión y desarticulación de gran parte de las experiencias de participación y acción colectiva- generó renovadas expectativas y activó el 
compromiso de una trama diversa de actores que pugnaron por otorgar unos sentidos particulares al proceso democrático abierto.

En este marco, a partir del análisis de algunos de estos conflictos y acciones colectivas que adquirieron visibilidad durante esos años, es posible dar cuenta de la confluencia de una variedad de trayectorias, experiencias e identidades políticas que en el contexto de reconstrucción de la democracia encontraron en el territorio y en las demandas por el acceso a la ciudad un espacio y una alternativa para la recuperación de la actividad política. De esta manera, la diversidad aparece como un rasgo distintivo de las redes de movilización activadas durante los años 80 en torno al hábitat popular. Entre otras trayectorias y experiencias, el movimiento se nutrió: del trabajo barrial desarrollado por la corriente católica de "opción por los pobres", en el marco de la tensión abierta en el seno de la Iglesia por la Teología de la Liberación; del acompañamiento a procesos de organización popular desde el saber técnico-profesional construido en la academia -fundamentalmente en el campo de la arquitectura y el urbanismo, así como en el trabajo social- y puesto al servicio de un horizonte de justicia y/o derechos; de los desarrollos alrededor de la educación y comunicación popular en América Latina en los años 60 y 70; de la militancia con horizontes de transformación radical de la sociedad desarrollada en los años 70 , con sus múltiples identidades partidarias, y también de la propia experiencia de los padecimientos y las restricciones en el acceso a una vida digna en los barrios y villas de Córdoba.

El proceso organizativo y contencioso desatado a partir del intento de desalojo en San Jerónimo en 1983, la elaboración y sostenimiento de la demanda de nuevas normativas que protegieran a los deudores hipotecarios indexados, la organización popular alrededor del derecho a acceder a servicios y equipamientos, entre otras experiencias de movilización, permiten observar en particular el papel de las organizaciones no gubernamentales en la puesta en marcha de ciertos mecanismos (reuniones, visitas de referentes de otras experiencias similares, producción de cartillas informativas y de capacitación) que incentivaron la conformación de estructuras de movilización en torno a problemas comunes en los barrios y villas. La acción de las ONG tuvo efectos en la socialización e incorporación de aprendizajes y competencias para la acción colectiva, así como en el fortalecimiento de los procesos organizativos locales mediante el asesoramiento técnico, la formación política y la producción de análisis que colaboraron en los procesos de identificación y construcción colectiva de las oportunidades políticas para la acción.

A lo largo de este artículo señalamos dos cuestiones que permiten comprender la relevancia -para estas experiencias de organización de sectores históricamente excluidos del acceso al hábitat- de los mecanismos de difusión (Tarrow, 2010; Mathieu, 2015) de ciertos marcos, repertorios de acción y formas organizativas que habían resultado exitosos en un contexto determinado. Por un lado, el papel de las ONG en la promoción de las organizaciones, la capacitación de dirigentes y la transferencia de recursos; por el otro, el contacto de los grupos de barrios y villas con otras experiencias de organización y lucha por el hábitat en otras regiones y momentos históricos. En la articulación de esas dos cuestiones se encuentra una de las claves de interpretación acerca de los procesos de configuración del hábitat como campo de experiencias en el período de recuperación de la democracia.

Por otra parte, el análisis de la coyuntura electoral de 1987 permitió dar cuenta de distintas alternativas de acción de los actores movilizados frente al dilema de la relación entre la construcción territorial de base y la participación en el sistema de partidos políticos. Si bien en estos años no aparece en el discurso de los actores el debate acerca de la "institucionalización" de los movimientos - al menos no como riesgo, puesto que existía un amplio consenso acerca de la necesidad de generar una institucionalidad democrática-, se planteaban algunas diferencias en la acción, así como en el tono de las advertencias acerca de los problemas de la manipulación de la dirigencia política respecto de las organizaciones de base. En este sentido, y más allá de las conceptualizaciones en disputa en el campo académico en torno a la relación entre lo social y lo político, es preciso reconocer que las concepciones sobre la política y la demarcación de sus fronteras respecto de otros “ámbitos" de lo social varían históricamente, y que esas variaciones impactan no sólo en las lecturas de los 
investigadores sobre los hechos sociales sino también en las propias maneras de pensar la política por parte de los sujetos protagonistas de la acción (Ferraudi Curto, 2012). En ese sentido, la política -y la democracia-son vividas y significadas en función de las posiciones de los actores y de los contextos de actuación, y se imponen sobre una variedad de prácticas vinculadas con las luchas por una ciudad más justa e igualitaria. Así, en estas primeras experiencias de organización popular postdictadura se hacen visibles las distintas trayectorias, horizontes y sentidos sobre la política que configuraron la acción conformando un campo de experiencias que articuló el trabajo social -territorial y comunitario- con la militancia política, vinculada a las estructuras partidarias históricas y nuevas. La constitución de un campo con estas características incidió en los modos de vinculación de los colectivos con los partidos políticos y el Estado, así como en la construcción de alianzas y estructuras de movilización de mayor escala.

Del mismo modo, en este período comienza a evidenciarse la confluencia - no siempre armónicade distintas lógicas de acción ${ }^{37}$ en el espacio urbano, que orientaron las protestas y la elaboración de justificaciones para el despliegue de la acción contenciosa: una lógica estratégica, vinculada con las necesidades y con la resolución de problemas concretos, relativamente independiente de adscripciones políticas; una lógica de la justicia, fundada públicamente en el sistema de derechos y en los principios de la Constitución recientemente restablecida, y una lógica ideológico-política, sustentada en principios ético-normativos relativos a la construcción de una sociedad y un sistema político verdaderamente democráticos. Esta confluencia en la diversidad de trayectorias, identidades, lógicas de acción, objetivos y sentidos sobre la política y la democracia configura un antecedente fundamental para comprender el desarrollo de experiencias de articulación y movilización desde los barrios y villas cordobesas en las décadas siguientes*.

\section{ReFERENCIAS}

Cecopal (1990). Esta tierra es nuestra. Córdoba: Cecopal.

Corcuff, P., y Sanier, M. (2000). Política pública y acción estratégica en contexto dedescentralización. Visiones de conjunto de una toma de decisiones 'después de la batalla'. Anales. Historia, Ciencias sociales, 55(4), 845-869. [Trad. Propia].

Di Virgilio, M., y Perelman, M. (2014). Ciudades latinoamericanas. La producción social de la desigualdad urbana. En M. Di Virgilio y M. Perelman (coord), Ciudades Latinoamericanas (9-23). Buenos Aires: CLACSO.

Ferraudi Curto, M. C. (2012). La urbanización de una villa en Buenos Aires y los sentidos de la política. Estudios Sociológicos, 30(88), 119-142.

Izaguirre, I., y Aristizabal, Z. (1988). Las tomas de tierras en la zona sur del Gran Buenos Aires. Buenos Aires: Centro Editor de América Latina.

Lefebvre, H. (1974). La producción del espacio. Papers: revista de sociología, 3, 219-229.

Mathieu, L. (2015). El espacio de los movimientos sociales. Intersticios, 9(2), 181-196. Recuperado de: http://www. intersticios.es/article/view/15548

Mc Adam, D., Tarrow, S., y Tilly, Ch. (2005). Dinámica de la contienda política. Barcelona: Hacer.

Melucci, A. (1999). Acción colectiva, vida cotidiana y democracia. México: El Colegio de México, Centro de Estudios Sociológicos.

Merklen, D. (1997). Organización comunitaria y práctica política. Las ocupaciones de tierras en el conurbano de Buenos Aires. Nueva Sociedad, 149, 162-177.

Mouffe, Ch. (2003). La paradoja democrática. Buenos Aires: Gedisa.

Pirez, P. (1995). Actores sociales y gestión de la ciudad. Ciudades. Red Nacional de investigación urbana, 28, 118-130.

Ré, M. C. y Taquela, M. E. (1998). Acceso a la tierra y construcción ciudadana: sistematización de una experiencia en servicios legales alternativos. Córdoba: Cecopal. 
Rinesi, E., y Vommaro, G. (2007). Notas sobre la democracia, la representación y algunos problemas conexos. En E. Rinesi, G. Nardacchione y G. Vommaro (comps.), Los lentes de Victor Hugo (pp. 419-472). Buenos Aires: Prometeo.

Schuster, F. (2005). Las protestas sociales y el estudio de la acción colectiva. En F. Schuster, F. Naishtat, G. Nardacchione, y S. Pereyra, Tomar la palabra. Estudios sobre protesta social y acción colectiva en la Argentina contemporánea (pp. 43-83). Buenos Aires: Prometeo.

Solís, C. (2013). Democracias en disputa: una aproximación a la experiencia del Movimiento Cordobés de los ochenta. Ponencia presentada en las II Jornadas Conjuntas del Área Historia del CIFFyH y Escuela de Historia, Córdoba, Argentina.

Tarrow, S. (2010). Dynamics of diffusion: mechanisms, institutions and scales shifts. En R. Givan, K. Roberts \& S. Soule (comps), The diffusion of social movements: actors, mechanisms and political effects [pp. 204-220]. Cambridge: Cambridge UniversityPress.

\section{Notas}

1 Las personas entrevistadas fueron: Ernesto Morillo (Mutual Mugica y Taller Carlos Mugica. Córdoba. 5/7/2013); Marco Galán (Mutual Mugica. Córdoba, 17/2/2012); Pedro Plaza (Uobds y Serviproh. Córdoba, 1/8/2014); Omar Flores (Uobds. Córdoba, 18/7/2014); Marcelo Mateo (Cecopal. Córdoba, 18/12/2012); Gabriela Rotondi (SeAP. Córdoba, 7/2/2015). En cuanto a las fuentes documentales, se relevaron las revistas Barrial $\left(\mathrm{N}^{\circ} 1,1984\right.$ a $\left.\mathrm{N}^{\circ} 11,1986\right)$; Aqui estamos los villeros ( $\left.\mathrm{N}^{\circ} 2,1985 \mathrm{a} \mathrm{N}^{\circ} 25,1990\right)$; El Indexado. Coordinadora de Loteos Indexados $\left(\mathrm{N}^{\circ} 7,1988\right.$ a $\mathrm{N}^{\circ}$ 21, 1990) y Tiempo Latinoamericano, $\mathrm{N}^{\circ} 18,1985$.Además, se analizaron documentos correspondientes a los archivos del SeAP, Cecopal y SEHAS. Las fuentes periodísticas utilizadas fueron los diarios La Voz del Interior y Córdoba.

2 Esta circular, emitida por el Banco Central en abril de 1980, instituyó un tipo de préstamo en el que las deudas hipotecarias se indexaban por la tasa de interés vigente en el mercado. La elevada tasa registrada en esos años implicó que las deudas crecieran exponencialmente, e incluso en algunos casos superaran el valor de las viviendas o terrenos adquiridos mediante el crédito.

3 El abogado Horacio Viqueira, promotor de las acciones legales en defensa de los vecinos indexados, había integrado en los 70 los Grupos de Base universitarios -identificados con la izquierda revolucionaria no peronista, en particular el PRT-, y luego se incorporó al PI.

4 Entre los fundadores de Cecopal estaban Arturo Bregaglio y Alfredo Paiva, que habían regresado del exilio con la recuperación de la democracia. Durante su exilio en Perú y otros países de Latinoamérica, ambos se habían involucrado en redes y experiencias de educación y comunicación popular, como Celadec y el Ceaal.

5 Ley 23.073 “Lotes y viviendas. Excepción a reajuste de precios”. Sancionada el 4/7/1984.

6 Folleto "La marcha de las villas", archivo del SeAP, 1985.

7 Volante de difusión de la Marcha Villera, archivo del SeAP, 1983.

8 Se trataba en este caso de la Fundación María Luisa Saavedra Zelaya de Carreras, vinculada a una familia de la alta sociedad porteña.

9 "Reclamo de villeros". La Voz del Interior, 14/07/1984, 12B.

10 "Desalojan a humildes. Denuncia de villeros", Córdoba, 7/7/1984; "Reclamo de villeros", La Voz del Interior, 14/07/1984, 12B; "Villeros: habría compromiso de no innovar hasta el 2 de agosto", La Voz del Interior, 10/7/1984; "Los villeros exigen ley de expropiación”, Córdoba, julio de1985 (archivo del SeAP).

11 Entre otros, el Partido Intransigente declaró a los medios su "solidaridad con las familias villeras" y exigió "una pronta intervención del gobierno provincial y municipal” (Córdoba, julio de 1985, archivo del SeAP). Por su parte la Asociación de Familiares de detenidos y desaparecidos por razones políticas de Córdoba distribuyó un volante en el que denuncia "la violencia de la oligarquía" y la "inhumana acción de los terratenientes nacionales", a la vez que expresa su solidaridad "por la verdad y la justicia” con los pobladores desalojados. (Documentos del archivo del SeAP)

12 Desde los primeros años de la dictadura, esta opción política dentro de la Iglesia católica se expresó en la constitución de las Comunidades Eclesiales de Base (CEBs), alrededor de las cuales se gestaron diversos procesos de organización en las villas y barrios populares. En el caso de las tomas de tierras en el Gran Buenos Aires, el compromiso de Monseñor Novak, obispo de Quilmes, junto con la acción sistemática de las CEBs resultó clave para el desarrollo de la experiencia organizativa en los asentamientos (Izaguirre y Aristizabal, 1988)

13 El SERPAJ y el SeAP fueron dos organizaciones creadas a comienzos de los años 80 como resultado de un acuerdo respecto a cierta "especialización institucional" (los derechos humanos y el trabajo comunitario, respectivamente).

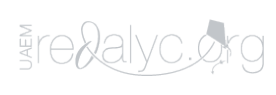


Ambas organizaciones tienen como origen común el Centro Ecuménico, que durante los últimos años de la dictadura fue uno de los espacios en los que se reunió la militancia barrial dispersa y amenazada por la represión.

14 Registro del Encuentro, archivo del SeAP.

15 Aqui estamos los villeros, $\mathrm{N}^{\circ} 2$, diciembre 1985 , editorial.

16 La cita corresponde a una editorial de 1986 en la que se exponen siete puntos para la discusión en las villas acerca de la relación de la CI con los partidos políticos. (“Aquí estamos los villeros”, № 4, octubre de 1986). Como veremos más adelante, un desplazamiento significativo respecto de estas concepciones sobre la democracia se expresará en la secuencia de acciones protagonizada por la CI en vísperas de las elecciones generales de 1987.

17 Entre otros: Sindicato del Calzado, Sindicato de Empleadas Domésticas y Sindicato de la Construcción (Aqui estamos los villeros, $\mathrm{N}^{\circ} 2, \mathrm{~N}^{\circ} 3$ y $\left.\mathrm{N}^{\circ} 4\right)$.

18 Este encuentro formó parte de una serie de actividades que dieron como resultado un Manifiesto con propuestas para el sector, que se presentó a los candidatos de todos los partidos para las elecciones de ese año.

19 "Propuestas del sector villero". Documento de conclusiones del Encuentro de Organizaciones Villeras, 25 y 26 de julio de 1987, Alta Gracia. Archivo del SeAP. Destacado en el original.

20 Testimonio de un dirigente villero participante en el Congreso Nacional de Estudiantes de Servicio Social. Barrial, N ○ 5 , abril de 1985.

21 La revista Barrial fue una experiencia de comunicación alternativa que durante los primeros años de la reconstrucción democrática congregó a militantes políticos con origen en el PRT-ERP, muchos de los cuales luego conformaron el Movimiento Cordobés, vinculado a la organización nacional Movimiento Todos por la Patria. La revista se publicó entre 1984 y 1988, y se distribuyó gratuitamente en distintos barrios de la ciudad de Córdoba.

22 Barrial $\mathrm{N}^{\circ} 2$ (diciembre 1984), $\mathrm{N}^{\circ} 3$ (febrero 1985), $\mathrm{N}^{\circ} 5$ (abril de 1985).

23 Barrial, $\mathrm{N}^{\circ} 12$, marzo de 1986.

24 "La Coordinadora de vecinos que reúne a más de 12 barrios de zona sur solicitó la inmediata restitución de las líneas de transporte que circulan por el sector. La asamblea consideró que "se han agotado todos los medios de diálogo para solucionar el conflicto". La Voz del Interior, 22/2/1986.

25 Barrial, $\mathrm{N}^{\circ}$ 6, junio de 1985.

26 Este es el título de tapa de la edición $N^{\circ} 6$ de la revista Barrial, dedicado a difundir los resultados del Encuentro Vecinalista.

27 En su nota dedicada al Encuentro Vecinalista, la Revista Tiempo Latinoamericano -una publicación del Centro del mismo nombre en el que se congregaban referentes y militantes católicos de la llamada "opción por los pobres"destacaba el compromiso de las organizaciones barriales con el proceso de democratización de las instituciones: "Después de años de represión y vaciamiento de las organizaciones barriales de bien común, el VECINALISMO en Córdoba se puso de pie para retomar su rica tradición de servicio y lucha en defensa de una auténtica democracia y de los intereses populares". (Revista Tiempo Latinoamericano $N^{\circ} 18$, año 3, julio 1985, p.18)

28 Entre otras acciones emprendidas en este marco se enviaron cartas a las comisiones vecinales, se recolectaron firmas, se realizaron conferencias de prensa y se presentaron petitorios en el Concejo Deliberante de la ciudad. Barrial, $\mathrm{N}^{\circ} 9$, octubre de 1985.

29 El Concejo Deliberante aprobó el 1 de octubre de 1985 la Ordenanza № 8125.

30 Barrial, $\mathrm{N}^{\circ}$ 6, junio de 1985.

31 El año 1987 fue para la Organización de las Nacionales Unidas el Año Internacional de los Sin Techo. Más allá de sus efectos prácticos sobre las condiciones de vida de las poblaciones más pobres, este llamado a la comunidad internacional movilizó a una diversidad de actores: ese mismo año, unas sesenta ONG de todo el mundo se reunieron en Kenia y formularon la Declaración de Limuru, en la que dejaron sentadas las posiciones y demandas de la sociedad civil vinculadas con la problemática del hábitat. Junto con ello, se constituyó la Coalición Internacional por el Hábitat (HIC, por su sigla en inglés), una red permanente para la generación de iniciativas y la interlocución con los Estados nacionales y los organismos internacionales.

32 Gacetilla de prensa enviada a los medios de Córdoba el 11 de agosto de 1987. Archivo del SeAP. Destacado en el original.

33 A la actividad pública de interpelación a los candidatos organizada por Intervillas en 1987 asistió en representación del Movimiento Cordobés Luis Miguel Baronetto, candidato a primer concejal. Baronetto era un militante de la Iglesia tercermundista que fue detenido y encarcelado durante la última dictadura. En los 80, coordinaba el Centro Tiempo Latinoamericano y la revista del mismo nombre.

34 Barrial, $\mathrm{N}^{\circ} 10$, diciembre de 1985, p. 2.

35 Barrial, $\mathrm{N}^{\circ} 14$, septiembre de 1986, p. 2.

36 Barrial, $\mathrm{N}^{\circ} 15$, noviembre de 1986. Destacado en el original.

37 Utilizamos aquí el concepto de lógicas de acción en un sentido aproximado al propuesto por Corcuff y Sanier (2000), que definen el régimen de acción como "la modelización de la acción en ciertas situaciones a través del equipo mental y gestual de las personas, en la dinámica de ajuste entre las personas y la situación”. Retoman el concepto de Boltanski 
y Thevenot, quienes postulan la pluralidad de "regímenes de acción" o "regímenes de compromiso" en el mundo social: régimen de justificación pública o de justicia, régimen de amor, régimen de violencia, régimen de familiaridad, etc.

* Quiero expresar mi reconocimiento y afecto a todas las personas entrevistadas, que colaboraron compartiendo sus vivencias y reflexiones. Agradezco la lectura atenta y los valiosos aportes de los evaluadores que me ayudaron a reorganizar el texto para garantizar una mayor claridad expositiva. Un agradecimiento especial a Gonzalo Assusa por el estímulo frente a cada desafio. 